\title{
Por uma Nova Compreensão do Conceito de Bem-estar: Martin Seligman e a Psicologia Positiva
}

\author{
Fabio Scorsolini-Comin ${ }^{1}$ \\ Universidade Federal do Triângulo Mineiro, Uberaba-MG, Brasil
}

Seligman, M. E. P. (2011). Florescer: Uma nova compreensão sobre a natureza da felicidade e do bem-estar (C. P. Lopes, Trad.). Rio de Janeiro: Objetiva.

Uma das melhores formas de comentar sobre este livro é apresentando o seu autor. Martin E. P. Seligman é psicólogo e professor da Universidade da Pensilvânia, nos Estados Unidos. A principal influência durante a sua formação foi a Psicologia Experimental, seguida pelos mais de 35 anos de prática clínica. Como professor de psicopatologia, certa vez indagou-se a respeito da tendência da ciência psicológica em focar seus estudos nas doenças, nos aspectos disfuncionais, desconsiderando aspectos positivos do desenvolvimento. Foi a partir da década de 1990 que seus questionamentos começaram a dar origem a uma nova corrente, intitulada Psicologia Positiva. E foi a partir de 1997, quando ocupou a presidência da American Psychological Association (APA), que seus estudos começaram a ser divulgados em todas as partes do mundo. Para a realização de suas pesquisas, recebeu apoio de importantes agências de fomento como o National Institute of Mental Health, National Science Foundation, Templeton Foundation, Robert Wood Johnson Foundation, Atlantic Philanthropies e MacArthur Foundation.

O movimento batizado de Psicologia Positiva surgiu oficialmente nos Estados Unidos, em 1997/1998, a partir da iniciativa de Seligman que, com outros pesquisadores, começou a desenvolver pesquisas quantitativas visando à promoção de uma mudança no foco atual da Psicologia. A proposta é da modificação desse foco de uma reparação dos aspectos ruins da vida para a construção de qualidades positivas ou virtudes (Seligman \& Csikszentmihalyi, 2000; Snyder \& Lopez, 2009). Desde o seu surgimento, a Psicologia Positiva não vem sendo divulgada apenas nos meios acadêmicos, desenvolvendo intervenções e propostas que convidam também os "não acadêmicos" a se beneficiarem de suas práticas. Um exemplo desse crescimento é a Associação Internacional de Psicologia Positiva (AIPP), que possui mais de três mil membros distribuídos em 70 países, reunindo não apenas pesquisadores, como profissionais da Psicologia e de diversas áreas interessados no estudo do bem-estar.

\footnotetext{
${ }^{1}$ Endereço para correspondência:

Prof. Dr. Fabio Scorsolini-Comin. Universidade Federal do Triângulo Mineiro. Instituto de Educação, Letras, Artes, Ciências Humanas e Sociais. Departamento de Psicologia do Desenvolvimento, da Educação e do Trabalho. Avenida Getúlio Guaritá, 159. CEP 38.025-440. Uberaba-MG, Brasil.E-mail: scorsolini_usp@yahoo.com.br
}

O livro em questão é dividido em duas partes, cada uma com cinco capítulos. Na primeira delas, intitulada Uma nova Psicologia Positiva, Seligman justifica o desenvolvimento de uma obra síntese sobre a Psicologia Positiva decorridos quase dez anos desde a publicação do livro Felicidade Autêntica (Seligman, 2002), traduzido para o português em 2004, que o consagrou como o maior expoente desta perspectiva teórica no mundo. Neste novo livro, Seligman inicia com uma mudança no objeto da Psicologia Positiva: em 2004, buscava-se a felicidade; atualmente, o termo empregado é o bem-estar. Essa mudança de nomenclatura surgiu a partir de diversos questionamentos que destacavam a felicidade como um conceito complexo de ser operacionalizado em termos de um construto psicológico. A expressão bem-estar, em contrapartida, possui uma aceitação maior nos meios científicos e acaba por resumir de modo mais adequado a proposta desse referencial. Uma nova definição de Psicologia Positiva seria, então, a ciência que investiga o bem-estar. No primeiro capítulo, o autor revela que o bem-estar pode ser mensurado em cinco fatores: emoção positiva, engajamento, sentido, relacionamentos positivos e realização. Desse modo, conceitua que o objetivo da Psicologia Positiva é aumentar o florescimento pelo aumento da emoção positiva, do engajamento, do sentido, dos relacionamentos positivos e da realização. Em suas palavras: "O bem-estar não pode existir apenas na sua cabeça: ele é uma combinação de sentir-se bem e efetivamente ter sentido, bons relacionamentos e realização. $\mathrm{O}$ modo como escolhemos nossa trajetória de vida é maximizando todos esses cinco elementos” (p. 36).

No segundo capítulo, apresenta exercícios que visam a aumentar o bem-estar e diminuir a depressão. Tais exercícios são direcionados tanto a leigos como a acadêmicos que têm desenvolvido programas de intervenção sob o enfoque da Psicologia Positiva. São apresentados alguns casos clínicos, bem como resultados dessas intervenções em diferentes contextos. A chamada Psicoterapia Positiva (PPT) é apresentada em 14 sessões com objetivos pontuais que visam a possibilitar que o paciente promova o seu florescimento, ou seja, que desperte para um modo de vida mais adaptativo e com a presença de emoções como bom humor, esperança, resiliência e otimismo. O terceiro capítulo se detém na explicitação de que os medicamentos e as psicoterapias tradicionais nem sempre buscam a cura, mas sim o alívio de sintomas. Essas 
intervenções são chamadas por Seligman de "cosméticas" justamente por levarem a resultados tímidos e que pouco contribuem para o efetivo bem-estar do paciente.

No quarto capítulo, o autor relata a experiência da criação, no ano de 2005, do primeiro programa de mestrado acadêmico em Psicologia Positiva Aplicada na Universidade da Pensilvânia (MAPP). Tratava-se de uma pós-graduação direcionada a pessoas que já estivessem engajadas no mercado de trabalho e que pudessem pagar o alto valor das mensalidades. Discutindo temas como o coaching em diferentes segmentos, bem como a importância de se desenvolver o bem-estar em escolas e universidades, o programa foi considerado revolucionário justamente por objetivar que as pessoas desenvolvessem seu potencial transformador. Amparado nos resultados desse programa, o capítulo 5 apresenta o relato de uma intervenção realizada na escola secundária de Geelong, na Austrália, com jovens. Com uma estrutura completa de docentes com formação em Psicologia Positiva, Martin Seligman liderou a criação de uma intervenção em tempo integral realizada ao longo de um ano na escola, a fim de comprovar a importância de que a escola também "ensinasse o bem-estar" aos seus jovens, ou seja, fomentando a implementação de uma educação chamada positiva.

Na segunda parte do livro, intitulada Formas de florescer, o autor discorre sobre a inteligência e de que modo o contexto contemporâneo tem privilegiado a velocidade, em vez do raciocínio e da qualidade. Sendo assim, apresenta a virtude da lentidão, uma metáfora que tem por objetivo conduzir à reflexão orientada para o futuro e não para o passado. O capítulo é ilustrado com diversos exemplos de intervenção, bem como resultados de programas desenvolvidos por Seligman e sua equipe. O capítulo 7 descreve o Programa de Aptidão Abrangente para Soldados, desenvolvido a partir da demanda de Jill Chambers, em 2008, então chefe do Programa do Pentágono para os soldados que retornam da guerra, bem como de George Casey, ex-comandante da força multinacional no Iraque. A intenção era criar um exército apto física e psicologicamente. A partir de um teste elaborado por Seligman, relatam-se os bons resultados obtidos com treinamentos de Psicologia Positiva, que tiveram como objetivo desenvolver recursos para o enfrentamento de situações de forte estresse emocional, tanto no trabalho como em família. Tal treinamento foi a base para a criação de outro programa, agora para ex-soldados com estresse pós-traumático, como descrito no capítulo 8. O foco do programa não era a situação de estresse, mas sim o crescimento que poderia ser buscado após o trauma. Desse modo, criou-se um treinamento em resiliência, de forma a ajudar que os ex-soldados desenvolvessem uma atitude mais positiva diante da vida e de suas adversidades, a partir de tópicos como a produção de resistência mental, luta conta pensamentos catastróficos, forças de caráter e produção de relacionamentos fortes.

O penúltimo capítulo trata da saúde física positiva e começa com o clássico questionamento acerca da definição de saúde da Organização Mundial da Saúde, proposta em 1946.
À ausência de doenças, Seligman acrescenta a presença de emoções positivas, conduzindo a um quadro de efetivo bem-estar. O autor recorre a diversos casos e estudos sobre doenças cardiovasculares, sobre o câncer e doenças infecciosas para propor que o foco exclusivo na doença nem sempre leva à cura e que emoções negativas como o pessimismo, ódio, rancor e depressão podem estar entre as causas de muitas doenças. Desse modo, com o foco na prevenção de doenças e na promoção da saúde, Seligman elenca alguns treinamentos que podem e devem ser desenvolvidos como forma de proteger a população, levando à adoção de uma postura otimista e diretamente ligada ao bem-estar.

Segundo seus estudos, as pessoas otimistas possuem atitudes e estilos de vida mais saudáveis e acreditam que as suas atitudes são importantes, ao contrário dos pessimistas. Os otimistas também atendem de modo mais adequado às prescrições médicas. Pessoas com alto grau de satisfação com a vida possuem maior probabilidade de cuidar da alimentação, não fumar e se exercitar com regularidade, tendo um sono mais regular. Os estudos sobre saúde positiva ainda estão em curso, com diversos questionamentos, mas já apontam para os efeitos benéficos da adoção de atitudes mais positivas no que se refere às condições de saúde. Estudos longitudinais conduzidos pelo autor e sua equipe são apresentados.

O último capítulo trata dos aspectos econômicos relacionados ao bem-estar, tentando responder à clássica pergunta sobre a relação entre dinheiro e felicidade. Embora os dados do Produto Interno Bruto (PIB) de um país possam revelar maiores investimentos em saúde, educação e bem-estar, Seligman recupera dados de países considerados pobres cuja população relata altos índices de satisfação com a vida. Assim, propõe que haja outros recursos que comprovem o desenvolvimento de um país que não apenas o PIB. O índice de satisfação com a vida, por exemplo, poderia ser utilizado para conhecermos onde estão as pessoas que se consideram mais felizes e quais as estratégias por elas utilizadas. O livro termina com uma versão reduzida do Teste de Forças Pessoais, elaborado pelo próprio autor, que apresenta itens que revelam as principais virtudes já desenvolvidas ou em processo de desenvolvimento, como sabedoria, conhecimento, gosto pela aprendizagem, originalidade, inteligência prática, engenhosidade, coragem, curiosidade, pensamento crítico, imparcialidade, entre outras.

O livro é rico em exemplos, exercícios, conversas com renomados pesquisadores da Psicologia, como Diener e Bruner, além de descrever casos e dados de mais de 30 anos de pesquisas que apresentam forte impacto no conhecimento científico internacional e que já chegaram ao Brasil em forma de diferentes estudos (Calvetti, Muller, \& Nunes, 2007; Dell'Aglio, Koller, \& Yunes, 2006; Scorsolini-Comin \& Santos, 2011).

Como uma perspectiva teórica ainda em florescimento, como sugere seu próprio criador, a Psicologia Positiva tem alcançado o respeito do meio acadêmico e aceitação de diversas pessoas que têm experienciado os resultados 
de suas intervenções. De jovens estudantes a ex-soldados, Seligman revela que o foco no adaptativo e naquilo que efetivamente "dá certo", para longe de um mero recurso de linguagem, pode trazer transformações sociais e pessoais importantes, em diferentes contextos. Obviamente, suas intervenções concentram-se em países como os Estados Unidos, que possibilitam o deslocamento de uma equipe inteira de docentes de uma universidade para a realização de um treinamento em uma escola, por exemplo, fato este ainda distante no contexto brasileiro. Feitas as devidas explicações de contexto, a Psicologia Positiva tem se mostrado uma alternativa para intervenções com foco no desenvolvimento das emoções positivas e nos bons relacionamentos. Para os mais céticos, Seligman se mostra extremamente disponível para o diálogo, disponibilizando gratuitamente mais de uma dezena de testes em seu site (http://www. authentichapiness.org) e convidando o leitor, já no início do livro, para escrever-lhe um e-mail (seligman@psych. upenn.edu) contando as suas impressões sobre o livro, com garantia de resposta quase imediata. Desse modo, fica o convite para a conversa, para a leitura e para uma reflexão mais aprofundada sobre o que é o bem-estar e como podemos desenvolvê-lo em nossas pesquisas e intervenções.

\section{Referências}

Calvetti, P. U., Muller, M. C., \& Nunes, M. L. T. (2007). Psicologia da Saúde e Psicologia Positiva: Perspectivas e desafios. Psicologia: Ciência e Profissão, 27(4), 706717. doi: 10.1590/S1414-98932007000400011

Dell'Aglio, D. D., Koller, S. H., \& Yunes, M. A. (2006). Resiliência e Psicologia Positiva: Interfaces do risco à proteção. São Paulo: Casa do Psicólogo.

Scorsolini-Comin, F., \& Santos, M. A. (2011). Casamento e satisfação conjugal: Um olhar da Psicologia Positiva. São Paulo: Annablume/FAPESP. Brasília: CNPq.

Seligman, M. E. P., Csikszentmihalyi, M. (2000). Positive Psychology: An introduction. American Psychologist, 55(1), 5-14. doi: 10.1037/0003-066X.55.1.5

Seligman, M. E. P. (2002). Authentic happiness: Using the new Positive Psychology to realize your potential for lasting fulfillment. London: Nicholas Brealey Publishing.

Snyder, C. R., \& Lopez, S. J. (2009). Psicologia Positiva: Uma abordagem científica e prática das qualidades humanas. (R. C. Costa, Trad.). Porto Alegre: Artmed.

Fabio Scorsolini-Comin é Professor Adjunto do Departamento de Psicologia do Desenvolvimento, da Educação e do Trabalho da Universidade Federal do Triângulo Mineiro.

Recebido: 03/04/2012

$1^{a}$ revisão: $15 / 07 / 2012$

Aceite final: 28/09/2012
Como citar:

Scorsolini-Comin, F. (2012). Por uma nova compreensão do conceito de bem-estar: Martin Seligman e a Psicologia Positiva. Paidéia (Ribeirão Preto), 22(53), 433-435. doi:http://dx.doi.org/10.1590/1982-43272253201315 